\title{
Fractures in Jamaican Males with Prostate Cancer: A Retrospective Case Series BF Morrison ${ }^{1}$, W Palmer ${ }^{2}$, S St. Juste ${ }^{2}$, M Reid ${ }^{3}$
}

\begin{abstract}
Objective: Androgen deprivation therapy (ADT) reduces bone mineral density in men treated for prostate cancer. We sought to determine if there was an ethnic difference in fractures induced by ADT in Jamaican men.
\end{abstract}

Methods: A retrospective analysis of orthopedic admissions to the University Hospital of the West Indies from 2000- 2009 was done. Eligible patients had a history of prostate cancer and ADT. Etiology of fractures was determined. Methods of treatment of prostate cancer and clinicopathological data were extracted from medical records.

Results: There were 13 admissions for fractures during the period and all were due to metastases. The mean duration of ADT use was $16.4 \pm 19.0$ (Range: 1-72) months. Conjugated estrogens were the most frequently used method of ADT however 55\% of patients were exposed to multiple types of ADT.

Conclusion: Fractures in Jamaican men with prostate cancer are rare and associated with metastatic disease.

Keywords: Androgen deprivation therapy, bone mineral density, fractures, prostate cancer From: ${ }^{1}$ Division of Urology, Department of Surgery, ${ }^{2}$ Division of Orthopedics, Department of Surgery, and ${ }^{3}$ Tropical Research Metabolism Unit, University of the West Indies, Kingston 7, Jamaica, West Indies.

Correspondence: Dr BF Morrison, Consultant Urologist and Lecturer, Department of Surgery University of the West Indies, Kingston 7, Jamaica, West Indies. 


\section{INTRODUCTION}

A total number of 1042 new cases of prostate cancer were recorded in the Kingston and St. Andrew region of Jamaica between 2003 and 2007 (1). This accounted for approximately $41 \%$ of all new cancers diagnosed in males in urban Jamaica. The burden of prostate cancer in Jamaica is great with a reported incidence rate of 78.1 per 100,000 men and mortality rate of 53.9 per 100,000 men $(1,2)$. Prostate cancer has been ranked as the leading cause of cancer in Jamaica over the past 3 decades (3).

Bone disease is common in men with prostate cancer (4). This may be due to osteoporosis secondary to androgen deprivation therapy (ADT) or metastatic disease that is still seen commonly in Jamaica. ADT is used widely in the treatment of locally advanced or metastatic prostate cancer as well as an adjuvant to external beam radiation therapy (5-7). It has also been found to be beneficial in men with nodal metastases after radical prostatectomy (8). Its use has also widened in elderly men with localized prostate cancer or in cases of biochemical recurrence post-curative treatment of localized prostate cancer (9). From 2000- 2007, 458 patients, representing approximately $67 \%$ of cases of prostate cancer were treated with ADT at the University Hospital of the West Indies, Kingston, Jamaica (10).

Traditional methods of delivery of ADT are via surgical castration (bilateral orchiectomy) or medical castration (gonadotropin releasing hormone-GnRH agonists, GnRH antagonists and steroidal or non-steroidal anti-androgens). Conjugated estrogens, though not widely used due to possible cardiovascular toxicity may be administered parenterally as a form of ADT. Chronic treatment with all forms of ADT, except estrogens results in reduction of bone mineral density within 6 months of treatment (11). This increases rates of skeletal fractures and increases mortality (12). 
Though there are demonstrable ethnic differences in bone mineral density, with persons of African descent having higher bone mass, this factor does not appear to be protective in African descent males on ADT for prostate cancer. We recently reported on decline in bone mineral density in Jamaican males with prostate cancer, treated with ADT (13). Although the association between ADT and osteoporosis has been established, we were still not aware of the burden of fractures in African-descent men on ADT for prostate cancer. Our aim was therefore to determine the burden and etiology of fractures in men treated with ADT for prostate cancer in Jamaica.

\section{METHODS}

Participants

This retrospective hospital-based case series included men with a histological diagnosis of adenocarcinoma of the prostate who were admitted to the Orthopedic Ward at the University Hospital of the West Indies, Kingston, Jamaica between January 1, 2000 and December 31, 2009. All patients were exposed to ADT.

\section{Data collection}

We reviewed data from patients' medical records as well as radiology films and reports. A Key exposure variable was the use of any form of ADT for prostate cancer. ADT was defined as exposure to surgical castration (bilateral orchiectomy) or medical castration (gonadotropin releasing hormone-GnRH agonists, GnRH antagonists, steroidal or non-steroidal anti-androgens and oral estrogens). Duration of ADT use was documented. Clinico-pathological data on prostate 
cancer including age at diagnosis, initial prostate specific antigen (PSA) level and Gleason score were recorded. Gleason score 2-4, 5-7 and 8-10 corresponded to well differentiated, moderately differentiated and poorly differentiated cancers, respectively. Key outcome variables were radiological diagnosis of fractures and prostate cancer-specific death.

\section{Measures}

Plain radiographs of all study patients were reviewed to determine the etiology and location of fractures. Fractures were classified as either due to metastases or osteoporosis. Sites of all metastatic deposits were recorded. Treatment of all orthopedic complications were recorded: radiation, surgery or conservative.

\section{Analysis}

Summary values are expressed as means with standard deviation or frequencies where appropriate. For categorical variables, we used Pearson's Chi squared statistics to assess association between exposure and outcome variables. We used multivariable logistic regression models to evaluate the association between exposure variables and the outcomes. Data were analyzed using Stata 12 for Windows (College Station, USA). The study was approved by the Ethics Committee, Faculty of Medical Sciences, University of the West Indies, Mona. 


\section{RESULTS}

A total of 40 males with adenocarcinoma of the prostate were admitted to the Orthopedic Ward at the University Hospital of the West Indies, Kingston Jamaica during the study period. Table 1 summarizes the baseline characteristics of the patients.

Table 1: Baseline Characteristics of prostate cancer admissions to Orthopaedic Ward- University Hospital of the West Indies (2000-2009)

\begin{tabular}{ll}
\hline Variables & Mean \pm (s.d.), median (IQR) or frequencies \\
\hline Age & $78.0 \pm 10.1$ years \\
PSA & $201.0 \mathrm{ng} / \mathrm{ml}(\mathrm{IQR}-510)$ (range: 2.8-14,260) \\
Gleason Score & $7.9 \pm 1.0$ \\
$\quad$ Well-differentiated (2-4) & 0 \\
$\quad$ Moderately differentiated & $34.6 \%$ \\
$\quad$ (5-7) & \\
$\quad$ Poorly differentiated (8-10) & $65.4 \%$ \\
\hline
\end{tabular}

\section{Primary prostate cancer treatment}

Only 2 patients had radical retropubic prostatectomy for treatment of initial localized prostate cancer.

Data on ADT use was available in 36 patients and all were exposed. Table 2 summarizes the frequencies and types of ADT used. Sixteen patients (44\%) were exposed to a single type of ADT during the study period. However, $12(33 \%)$ and 8 (22\%) were exposed to 2 and 3 types of ADT, respectively. The mean duration of ADT use was $16.4 \pm 19.0$ (Range: 1-72) months. 
Table 2: Androgen Deprivation Therapy (ADT) in Orthopaedic Admissions to the University Hospital of the West Indies (2000-2009)

\begin{tabular}{ll}
\hline Types of ADT & $\%$ \\
\hline Surgical Castration & $14(38.9)$ \\
Anti-androgens & $17(47.2)$ \\
Luteinizing hormone releasing hormone & $9(25.0)$ \\
(LHRH) analogue & \\
Oestrogens & $24(66.7)$ \\
\hline
\end{tabular}

\section{Fractures}

There were 13 patients $(32.5 \%)$ who were noted to have fractures. Radiological assessment revealed that all fractures were pathological and associated with bony metastases. The femur was the most common fracture site. No fracture was observed in the absence of metastatic deposits. Radiological evidence of metastases were evident in 33 patients. Fractures were treated with dynamic hip screws in 2 patients, an intramedullary nail in 1 patient and conservatively in the remaining patients. The remaining 27 patients who were not diagnosed with fractures were admitted for evidence of spinal cord compression or severe pain in association with metastatic disease. Eleven (11) patients received external beam radiation either for fractures or bony metastases.

There was no association between oestrogen use and the outcome of fractures. There was a trend towards association of LHRH use and fracture $(\mathrm{p}=0.07)$. Fourteen (14) had prostate cancer-specific deaths during the study period. There was no association between death and fractures. 


\section{DISCUSSION}

The present study revealed a low fracture rate in Jamaican men with prostate cancer who were treated with ADT. In addition, there were no cases of osteoporotic fractures noted in these men. The results are in contradiction with large cohort and case control studies in other centers. In a large retrospective cohort study including 50, 613 men with prostate cancer listed in the National Cancer Institute's Surveillance, Epidemiology, and End Results (SEER) program and Medicare, of men surviving beyond 5 years of diagnosis there was a significantly increased risk of fractures in men exposed to ADT (19.4\% versus $12.6 \%)(12)$. Similarly in a systematic review of skeletal adverse effects of ADT, the findings revealed that men on ADT for prostate cancer had an increased risk of overall fractures of $23 \%$ (RR- 1.23; [95\% CI], 1.10-1.38) (14).

Prostate cancer is commonly seen in middle-aged and elderly males and these men are

vulnerable to fragility fractures which increase with advancing age (15). There are genetic differences in osteoporosis with African ethnicity being protective (16). The Tobago Bone Health Study reported that bone mineral density was 10-20\% higher in African Caribbean males compared to U.S. non-Hispanic black and white males, respectively (16). Nam et al demonstrated that these ethic differences were even greater when comparing Afro-Caribbean males to Asian males (17). Despite the advantage of a higher baseline bone mineral density in Afro-Caribbean men, the rate of decline with advancing age appears to be comparable between African-Caribbean and Caucasian males (18).

GnRH agonists which are the most commonly prescribed form of ADT in Jamaica and internationally, increase bone turnover by increasing parathyroid hormone-mediated osteoclast activation $(10,19,20)$. Bilateral orchiectomy causes a similar accelerated bone turnover (21). Bone mineral density at the hip and spine reduces steadily at a rate of $2-3 \%$ annually in men 
treated with ADT (22). There appears to be a similar decline in largely Afro-Caribbean populations. The Tobago Bone Health study reported a significant decline in bone mineral density in men with prostate cancer treated with ADT compared with their counterparts (18). We previously reported reduced bone mineral density in Jamaican men on ADT for prostate cancer compared to controls (13).

In spite of the osteoporosis that is induced by the hypogonadal state in these men, there is very little data on increased fracture risk in men of African ethnicity treated with ADT. Many of the reported large retrospective cohort studies evaluating fracture risk in men on ADT have men of African ethnicity underrepresented or perform no adjustment for the confounder of race in their analysis. Baseline data on the distribution of osteoporotic fractures in Jamaica show a preponderance of female patients with few fractures being due to the osteoporotic effect of ADT in prostate cancer patients $(23,24)$. We hypothesize that fractures due to ADT use in men of African ethnicity may be less common due to the protective effect of a higher initial bone mineral density.

Our results reveal that over $60 \%$ of patients were treated with the conjugated estrogen, Premarin ${ }^{\circledR}$ for prostate cancer. Oral estrogens found widespread use in the form of diethylstilbestrol many years ago in the management of patients with metastatic prostate cancer (25). The primary mechanism of action of estrogens was suppression of the hypothalamopituitary gonadal axis. Unfortunately, early studies with diethylstilbestrol utilized a high dose of $5 \mathrm{mg}$ and this induced hepatic pro-coagulant proteins which increased thrombosis and cardiovascular events (26). These agents therefore have largely been replaced by GnRH analogues. However, their use is continued in Jamaica as the agents are cheap, appear to have minimal cardiovascular adverse effects and have been useful for second-line hormonal 
manipulation. Estrogens are also directly cytotoxic to prostate cancer cells (27). Recent evidence suggests that parenteral estrogen administration maintains efficacy while avoiding cardiovascular toxicity $(28,29)$. Even more beneficial is the osteoporotic-sparing effect of estrogens (21). Estrogens maintain normal bone metabolism and since both osteoblasts and osteoclasts have estrogens receptors, their function is modulated by them $(30,31)$. The effect of estrogens on fracture risk is still unknown. There was no associated protective effect of estrogen use on fracture outcome in our study. This null effect could possibly be due to a small sample size. We suggest that the continued widespread use of oral conjugated estrogens in Jamaica for prostate cancer may offer protection from fractures in these men.

Our study had several limitations. Its retrospective nature precluded any assessment of fracture risk. This would have ideally been possible with a cohort or case-control study design. We are aware that our sample size of 40 men was small but it reflects the rarity of the condition in a setting where prostate cancer and ADT use is highly prevalent. Our study was a hospitalbased and we are aware that this could provide a selection bias where asymptomatic fractures could be missed in patients not presenting to hospital, which is particularly likely in osteoporotic spinal fractures. Measurement bias could have occurred with the assessment of osteoporosis being made through radiographs and not DEXA at multiple sites. Misclassification could occur as the metastatic deposits could have developed after the osteoporotic fracture has occurred especially in the region of the spine where both pathologies are common. Due to the retrospective nature of the study, we were unable to assess for confounders such as glucocorticoid or alcohol use, other malignancies, endocrine disorders, activity level, smoking history or chemotherapy. 


\section{CONCLUSION}

Osteoporotic fractures are uncommon in Jamaican males treated with ADT for prostate cancer. Additional cohort studies are needed to evaluate the effects of ADT in men of African-ethnicity. 


\section{REFERENCES}

1. Gibson TN, Hanchard B, Waugh N, McNaughton D. Age-specific incidence of cancer in Kingston and St. Andrew, Jamaica, 2003-2007. West Indian Med J 2010; 59: 456-64.

2. Blake G, Hanchard B, Mitchell K, Simpson D, Waugh N, Wolff C, et al. Jamaica cancer mortality statistics, 1999. West Indian Med J 2002; 51: 64-7.

3. Gibson TN, Hanchard B, Waugh N, McNaughton D. Thirty-year trends in incidence and age-distribution of prostate cancer in Kingston and St Andrew, Jamaica, 1978-2007. West Indian Med J 2011; 60: 9-12.

4. Saylor PJ, Smith MR. Bone health and prostate cancer. Prostate Cancer Prostatic Dis 2010; 13: 20-7.

5. Huggins C. Effect of Orchiectomy and Irradiation on Cancer of the Prostate. Ann Surg 1942; 115: 1192-200.

6. Bolla M, Collette L, Blank L, Warde P, Dubois JB, Mirimanoff RO, et al. Long-term results with immediate androgen suppression and external irradiation in patients with locally advanced prostate cancer (an EORTC study): a phase III randomised trial. Lancet 2002; 360: 103-6.

7. D'Amico AV, Manola J, Loffredo M, Renshaw AA, DellaCroce A, Kantoff PW. 6-month androgen suppression plus radiation therapy vs radiation therapy alone for patients with clinically localized prostate cancer: a randomized controlled trial. JAMA 2004; 292: 821-7.

8. Messing EM, Manola J, Yao J, Kiernan M, Crawford D, Wilding G, et al. Immediate versus deferred androgen deprivation treatment in patients with node-positive prostate 
cancer after radical prostatectomy and pelvic lymphadenectomy. Lancet Oncol 2006; 7: 472-9.

9. Zincke H, Oesterling JE, Blute ML, Bergstralh EJ, Myers RP, Barrett DM. Long-term (15 years) results after radical prostatectomy for clinically localized (stage T2c or lower) prostate cancer. J Urol 1994; 152: 1850-7.

10. Morrison BF, Aiken WD, Reid ME. Impact of the National Health Fund policy on hormone treatment for prostate cancer in Jamaica. Rev Panam Salud Publica 2011; 29: 404-8.

11. Mittan D, Lee S, Miller E, Perez RC, Basler JW, Bruder JM. Bone loss following hypogonadism in men with prostate cancer treated with GnRH analogs. J Clin Endocrinol Metab 2002; 87: 3656-61.

12. Shahinian VB, Kuo YF, Freeman JL, Goodwin JS. Risk of fracture after androgen deprivation for prostate cancer. N Engl J Med 2005; 352: 154-64.

13. Morrison BF, Burrowes IE, Aiken WD, Mayhew RG, Fletcher HM, Reid ME. Bone mineral density in Jamaican men on androgen deprivation therapy for prostate cancer. Infect Agent Cancer 2011; 6 Suppl 2: S7.

14. Taylor LG, Canfield SE, Du XL. Review of major adverse effects of androgendeprivation therapy in men with prostate cancer. Cancer 2009; 115: 2388-99.

15. Ebeling PR. Clinical practice. Osteoporosis in men. N Engl J Med 2008; 358: 1474-82.

16. Hill DD, Cauley JA, Sheu Y, Bunker CH, Patrick AL, Baker CE, et al. Correlates of bone mineral density in men of African ancestry: the Tobago bone health study. Osteoporos Int 2008; 19: 227-34. 
17. Nam HS, Shin MH, Zmuda JM, Leung PC, Barrett-Connor E, Orwoll ES, et al. Race/ethnic differences in bone mineral densities in older men. Osteoporos Int 2010; 21: 2115-23.

18. Sheu Y, Cauley JA, Wheeler VW, Patrick AL, Bunker CH, Kammerer CM, et al. Natural history and correlates of hip BMD loss with aging in men of African ancestry: the Tobago Bone Health Study. J Bone Miner Res 2009; 24: 1290-8.

19. Sharifi N, Gulley JL, Dahut WL. Androgen deprivation therapy for prostate cancer. JAMA 2005; 294: 238-44.

20. Leder BZ, Smith MR, Fallon MA, Lee ML, Finkelstein JS. Effects of gonadal steroid suppression on skeletal sensitivity to parathyroid hormone in men. J Clin Endocrinol Metab 2001; 86: 511-6.

21. Eriksson S, Eriksson A, Stege R, Carlstrom K. Bone mineral density in patients with prostatic cancer treated with orchidectomy and with estrogens. Calcif Tissue Int 1995; 57: 97-9.

22. Smith MR, McGovern FJ, Zietman AL, Fallon MA, Hayden DL, Schoenfeld DA, et al. Pamidronate to prevent bone loss during androgen-deprivation therapy for prostate cancer. N Engl J Med 2001; 345: 948-55.

23. Williams-Johnson JA, Wilks RJ, McDonald AH. Falls: A modifiable risk factor for the occurrence of hip fractures in the elderly. West Indian Med J 2004; 53: 238-41.

24. O'Connor I, McDowell D, Barnes D. Hip Fractures: The St Ann's Bay Regional Hospital Experience. West Indian Med J 2014; 63: 138-41.

25. Schwartz M. The effect of stilbestrol on the testis and breast of patients treated for carcinoma of the prostate gland. Proc Am Fed Clin Res 1945; 2: 97. 
26. Byar DP. Proceedings: The Veterans Administration Cooperative Urological Research Group's studies of cancer of the prostate. Cancer 1973; 32: 1126-30.

27. Schulz P, Bauer HW, Brade WP, Keller A, Fittler F. Evaluation of the cytotoxic activity of diethylstilbestrol and its mono- and diphosphate towards prostatic carcinoma cells. Cancer Res 1988; 48: 2867-70.

28. Langley RE, Godsland IF, Kynaston H, Clarke NW, Rosen SD, Morgan RC, et al. Early hormonal data from a multicentre phase II trial using transdermal oestrogen patches as first-line hormonal therapy in patients with locally advanced or metastatic prostate cancer. BJU Int 2008; 102: 442-5.

29. Hedlund PO, Damber JE, Hagerman I, Haukaas S, Henriksson P, Iversen P, et al. Parenteral estrogen versus combined androgen deprivation in the treatment of metastatic prostatic cancer: part 2. Final evaluation of the Scandinavian Prostatic Cancer Group (SPCG) Study No. 5. Scand J Urol Nephrol 2008; 42: 220-9.

30. Eriksen EF, Colvard DS, Berg NJ, Graham ML, Mann KG, Spelsberg TC, et al. Evidence of estrogen receptors in normal human osteoblast-like cells. Science 1988; 241: 84-6.

31. Oursler MJ, Pederson L, Fitzpatrick L, Riggs BL, Spelsberg T. Human giant cell tumors of the bone (osteoclastomas) are estrogen target cells. Proc Natl Acad Sci U S A 1994; 91: 5227-31. 